\title{
EL PAPEL DEL SIMBOLISMO \\ EN LA FILOSOFÍA DE NISHIDA KITARÕ
}

\author{
MONTSERRAT CRESPÍN PERALES \\ Universidad de Barcelona
}

\begin{abstract}
RESUMEN: Como alternativa a los múltiples acercamientos y estudios sobre la filosofía de NISHIDA Kitarõ (1870-1945), en este trabajo se quiere presentar un avance de investigación sobre una cuestión normalmente obviada en las interpretaciones de la obra del filósofo. Se querrá mostrar cómo una mirada atenta a la idea de símbolo y las menciones a la poesía simbolista en la obra de Nishida ofrecen una clave plausible para una mejor comprensión de su sistema de la autoconciencia en obras como Intuición y reflexión en la autoconciencia (1917) o Los problemas de la conciencia (1920).
\end{abstract}

PALABRAS CLAVE: Nishida Kitarõ; filosofía japonesa; autoconciencia; poesía simbolista; Japón moderno.

\section{The role of symbolism in the philosophy of Nishida Kitaro}

ABSTRACT: As an alternative to the multiple studies about the philosophy of NISHIDA Kitarõ (18701945), this essay wants to present a research line about questions not normally considered in the interpretation of his philosophy. The intention is to demonstrate how a close look to the idea of «symbol» and the citations of symbolist poetry in Nishida's works can offer a plausible key for a better comprehension of his selfconsciousness system that appears in works as Intuition and Reflection in Self-consciousness (1917) or Problems of consciousness (1920).

KEY WORDS: Nishida Kitarõ; Japanese philosophy; Self-consciousness; Symbolist Poetry; Modern Japan.

\section{LA PREgUNTA SOBRE LA CONEXIÓN ENTRE LA FILOSOFÍA DE NiSHIDA Y EL SIMBOLISMO}

En las siguientes páginas quisiera indicar algunos puntos básicos que conectan la filosofía de Nishida Kitarõ $(1870-1945)^{1}$ con la recepción del movimiento literario simbolista en Japón y que surgieron a medida que avanzaba en el estudio de las primeras obras del filósofo.

Para comenzar, decir que aquí se apuntarán cuestiones que acercarán temas normalmente tratados académicamente por separado. Por un lado, en los estudios sobre literatura moderna japonesa y, en particular, los centrados en la poesía, y, por otro, en ensayos que interpretan y exponen aspectos propios del pensamiento japonés. Por evidente que sea la ligazón entre los estudios literarios y la filosofía no siempre se ponen en diálogo sus ámbitos académicos o, desde la filosofía en sentido estricto, solamente se hace en el campo de la estética. En lo referente a la interpretación de los textos filosóficos nishidianos, la intercomunicación entre la literatura y la estética es algo aún no suficientemente

1 Este texto sigue el orden tradicional en japonés de anteponer el apellido al nombre. Para prevenir confusiones, siempre que se dé el nombre íntegro de un autor, el apellido aparecerá en versalitas. 
analizado aunque tenemos a nuestra disposición excelentes trabajos de buenos conocedores de la historia del pensamiento y la literatura japoneses que sí tratan algunos aspectos significativos al respecto 2 .

La intuición básica que me movió a preguntarme sobre qué era aquello que propiciaba que Nishida citara dispersamente a algunos poetas y al simbolismo como movimiento literario surgió, como ya se ha dicho, tras la lectura atenta de algunos de sus primeros ensayos. En concreto, fue a consecuencia del análisis extenso de su noción y sistematización de la idea de «autoconciencia» (jikaku-自覚) y de la particular relación de esta noción con la conceptualización de símbolo tal y como aparece en su obra Intuición y reflexión en la autoconciencia (Jikaku ni okeru Chokkan to Hansei) [自覚に於ける直観と反省] (1917)3.

A causa de la necesidad de síntesis expositiva de este estudio, no será posible entrar en algunos de los muchos detalles genealógicos que conforman la idea de «autoconciencia» nishidiana y su centralidad durante su primera etapa de producción filosófica que se puede datar del 1911 al $1927^{4}$. Lo que sí que se intentará es una aproximación plausible, y ese será el objetivo de este texto, que cuestione en qué medida las referencias al movimiento simbolista que hace el filósofo le ayudan a apuntalar algunas cuestiones fundamentales sobre la noción de "autoconciencia» y la construcción de su idea de sujeto desde una perspectiva epistemológica, ética y estética.

Para ello será importante fijarse y contextualizar los referentes literarios y los tropos de la poesía simbolista que el filósofo menciona. Deberán servir para averiguar cómo sirven a la trabazón esencial entre epistemología y ontología tan palpable en sus ensayos. Y será oportuno analizar si la idea misma de símbolo y sus correspondencias lingüístico-cognoscitivas poéticas que prefigura Nishida con sus sucintas citaciones de los poetas simbolistas europeos, no son más que una cuestión aislada en los márgenes de su obra filosófica o bien este

2 Pensamos en la obra de especialistas en activo como K. Kõjin, S. Sadami, M. F. Marra, R. F. Calichman, S. Odin o I. Ken'ichi. Éste último, en uno de los pocos ensayos extensivos sobre la filosofía de Nishida y la estética, señala que en lo referente a la filosofía de Nishida y, por extensión, al círculo de pensadores relacionados con la Escuela de Kyoto, aún son escasos los estudios que analizan la relación de su corpus filosófico con la estética y la filosofía del arte. Véase, Ken'ICHI, I., «Nishida Kitarõ and Art», en MARRA, M. F. (Ed. \& Transl.), A History of Modern Japanese Aesthetics, Hawaii University Press, Honolulu 2001, pp. 259-284.

3 Jikaku ni okeru Chokkan to Hansei en Nishida, Kitarõ, Nishida Kitarõ Zenshû; YoSHISHIGE, A. to Henshû, Vol. 2, Iwanami Shoten, Tokyo 1965, y traducción al inglés de la obra en Kitarõ, N., Intuition and Reflection in Self-consciousness; Translated by Valdo H. Viglielmo with Takeuchi Yoshinori and Joseph S. O'LEARY, State University of New York, New York 1987

4 Como sucede con toda sistematización periódica, tampoco hay unanimidad en cuanto a la fijación de periodos respecto a la obra de Nishida. No obstante, la mayoría de los estudiosos coinciden en fijar el primer periodo en el comprendido entre 1911, cuando publica Estudio sobre el Bien (Zen no Kenkyû) [善の研究], su primera obra, y el año 1927, cuando sale a la luz Del hacer al mirar (Hataraku mono kara miru mono e) [働くものから見るものへ]. Así se considera también en este trabajo. 
indicio se entreteje de una manera más amplia en la historia intelectual (literaria y filosófica) del Japón moderno.

Para poder ofrecer algunas guías sobre lo anterior, la metodología más idónea sería aquella que investigara las ideas fundamentales de los textos filosóficos de Nishida usando el procedimiento reconstructivo tal y como lo plantea el historiador de filosofía alemana Dieter Henrich. Cuestionándose sobre algunos de los problemas más complejos de la filosofía kantiana, Henrich indica que la idoneidad del procedimiento reconstructivo recae, en primer lugar, en tratar de asignar definiciones clarificadoras de aquellos conceptos que pueden aparecer como ambiguos para, luego, aislar las premisas y argumentos que pespuntean la complejidad textual. Con tal método interpretativo se aspira a ofrecer un comentario filosófico capaz de mostrar algunas explicaciones válidas para iluminar el esquema que conformó la originaria construcción de ideas del filósofo ${ }^{5}$ tal cual se leen en las páginas de su obra.

Aquí se seguirá este método en lo tocante a la asignación de definiciones clarificadoras de los conceptos y nociones fundamentales y, asimismo, se tratarán de aislar las premisas y argumentos básicos y necesarios para desentrañar una parte de la complejidad inherente al estilo filosófico nishidiano y, en concreto, respecto a las relaciones entre su noción de «autoconciencia» $\mathrm{y}$ "subjetividad» con el simbolismo. Se añadirá, también, una perspectiva histórica que ayude a contextualizar de qué modo entra en la escena intelectual japonesa el movimiento literario simbolista y el trayecto de su conceptualización literariofilosófica.

Ahora bien, dada la necesaria acotación del tema y, a su vez, la obligada brevedad de este trabajo, el comentario reconstructivo de algunas de las vicisitudes filosóficas deberá dejar fuera muchos detalles para primar una lectura y comentario necesariamente más general y expositivo pero, a los efectos de lo que se quiere decir, con el deseo de facilitar una interpretación clara al menos sobre los rasgos principales.

\section{La CONCEPTUALIZACión DE «Símbolo» (shõchõ-象徵) EN EL JAPÓN MEIJI}

De acuerdo con el estudio de Earl Jackson, Jr. sobre la poesía simbolista japonesa, la conceptualización de «símbolo» (shõchõ-象徵) surge en paralelo a algunos conceptos filosóficos esenciales que se tradujeron o, podríamos decir también, sobre los que se buscó transliterar ${ }^{6}$ su sentido, en lengua japonesa durante el Japón Meiji (1868-1912).

5 HenRich, D., «Identity and Objectivity: An Inquiry into Kant's Transcendental Deduction» (1976), en The Unity of Reason. Essays on Kant's Philosophy; VelkLey, R. L. (Ed.), Edwards, J., Hunt, L., Kuehn, M. and Zoeller, G. (Transl.), Harvard University Press, London 1994, p. 124.

6 Entendiendo aquí el sentido de «transliterar» como representar los signos de un sistema significante de escritura mediante los signos de otro, comportando esa representación una presentación de su significado y sentido más allá de la sola acción de «traducir», si se 
En su investigación, Jackson relaciona recíprocamente los procesos de construcción del vocablo metafísica (keijijõgaku-形而上学) y símbolo. Según su tesis principal, las vicisitudes históricas de ambas nociones coinciden tanto en su dinámica, que busca acomodar un concepto proveniente de lenguas occidentales al japonés, como en el campo de las posibles intersecciones o coalescencias entre lo estrictamente poético (símbolo) y lo filosófico (metafísica) ${ }^{7}$.

Así, si atendemos a la importantísima tarea llevada a cabo por NisHi Amane (1829-1897) para dar forma a numerosos neologismos, entre los que está la misma palabra «filosofía» (tetsugaku-哲学), este pensador, al enfrentarse a la traducción de «metafísica», dudó ampliamente hasta llegar a la que sigue siendo su forma terminológica actual, keijijõgaku. En su dubitación sobre cómo traducir y qué neologismo crear para referir a la «metafísica», no es descabellado intuir que, como le sucedió al traducir «filosofía», «lógica» o «estética», el peso del confucianismo de Nishi tuvo que contrarrestarse con su simpatía por el positivismo de Comte o Mill ${ }^{8}$ que él ayudó a introducir en Japón. Con toda seguridad hubo al buscar el término un intento por evitar trasponer, con el vocablo elegido, las connotaciones de la metafísica en la historia filosófica occidental y su inherente dualismo separativo de la trascendencia y la inmanencia. Pero, a pesar de las suspicacias que Nishi pudiera tener en estos primeros años de recepción e irrupción de la filosofía «occidental» y, especialmente, de conformación de la terminología filosófica, en el vocablo escogido para «metafísica» es patente la clara separación que se introduce entre lo trascendente y lo inmanente.

Lo inmanente, entendido como lo físico o material (keijika-形而下), está abajo (shita-下) y aquello otro que está más allá de la forma física y que es, por tanto, metafísico (keijijo--形而上), está «por encima de»o «arriba» (ue-上). La introducción de un concepto con tanta carga ontológica significante conlleva necesariamente, con su inserción y uso lingüístico posterior, el establecimiento de una fuerte estructura filosófica, la de la trascendencia, con no pocas

entiende ésta como la pura «conversión» expresiva en una lengua de aquello que está escrito o expresado antes en otra.

7 Véase JACKSON, E., JR., «The Metaphysics of Translation and the Origins of Symbolist Poetics in Meiji Japan», PMLA (Modern Language Association), Vol. 105, No. 2 (Mar., 1990), pp. 256-272.

8 González Valles, J., Historia de la filosofía japonesa, Tecnos, Madrid 2002, p. 200: «Antes de Nishi había en la lengua japonesa palabras apropiadas para expresar conceptos filosóficos occidentales y él se impuso la dura tarea de enriquecer el vocabulario patrio con tecnicismos trasladados directamente de las lenguas europeas. (...) Si exceptuamos la terminología que él mismo trasladó directamente de las lenguas occidentales al japonés, la mayor parte de su vocabulario técnico tiene la impronta confuciana. Incluso recurre al principio $L i$ (o $R i$ ) para explicar la relación entre un ser y otro. Si quisiéramos definir sucintamente la personalidad de Nishi como filósofo, diríamos que fue un positivista ecléctico y un idealista en ciernes». Véase también respecto a la creación de la terminología filosófica y el eclecticismo de Nishi, Piovesana, G., Recent Japanese Philosophical Thought 1862-1962. A Survey. With a New Survey (1963-96) by Naoshi YamaWAKI; 3rd. Revised Edition, Japan Library-Curzon Press, Richmond Surrey 1997, pp. 11-18. 
consecuencias que se aprecian claramente a medida que avanza el pensamiento filosófico japonés durante las últimas décadas del siglo XIX y la primera mitad del siglo XX. Porque, a un nivel básico, la trascendencia remite a un principio u orden de cosas que se encuentra más allá de los límites de lo puramente fenoménico, físico, factual o, si se prefiere, material. La introducción de esta mirada hacia la «trascendencia» connotativamente tan fuerte, y el dualismo clásico inmanente/trascendente, suscitará no pocos debates filosóficos entre los pioneros del estudio e interpretación de la filosofía occidental en Japón. Sucede, por ejemplo, en el caso de dos pensadores como Inoue Enryõ (1858-1919) e Inoue Tetsujirõ (1856-1944). Ellos pugnaron por encontrar un corpus filosófico japonés, propiamente «nacional», capaz de quedar enmarcado entre el buddhismo y el método filosófico pero queriéndose diferenciar del cristianismo. Por aquel entonces, algunos intelectuales como los citados vieron con recelo la potencia ideológica, teológica y filosófica del cristianismo.

Encontramos una problemática similar a la de la traducción de metafísica cuando fijamos la atención en el proceso de traducción de «símbolo» que, en este caso, fue realizado por otro eminente filósofo, NAKAE Chõmin (1847-1902). Tal y como explica Jackson, Nakae acuña el vocablo al traducir, entre 1883 y 1884, la obra de Eugène Véron (1825-1879), L'esthétique (1878) ${ }^{9}$. Incluso añade al texto original de Véron una coda explicativa sobre el significado exacto del término "símbolo» a fin de facilitar la comprensión del lector japonés ${ }^{10}$. Para Nakae, «símbolo» (shõchõ-象徵), en el contexto del texto de Véron que en ese punto refiere a la escritura egipcia, remite a la acción de crear un signo que toma como patrón la forma de un objeto.

Atendiendo a los dos kanji que componen el término, vemos que Nakae, con la conceptualización y creación del neologismo, persigue mantener unidos el fenómeno (la pura cosa, el objeto) (shõ-象) y aquello otro que lo indica, lo evidencia, lo marca o significa como signo lingüístico (shirushi-徵). Se debe

9 La traducción del texto de Véron que hizo Nakae es de una importancia significativa en el contexto de la literatura japonesa. Supuso, entre otras cosas, el interesante debate, fuertemente centrado en conceptos filosóficos, que mantuvieron durante los años 1891 y 1892 dos figuras centrales de la historia de la literatura japonesa moderna: SHõyõ, T. (18591935) y ÕGAI, M. (1862-1922). Tsubouchi y Mori contrapusieron sus perspectivas sobre cómo concebir la literatura en diversos artículos publicados en las páginas de las revistas literarias Waseda bungaku y Shigarami Zõshi. Mientras que Mori defendía la perspectiva de la filosofía idealista de autores como Eduard von Hartmann (1842-1906) y el papel de la literatura como medio para discutir «ideas», Tsubouchi defendía que la literatura debía ser más bien el espacio para la descripción de «hechos», siguiendo en esto la línea crítica contra el idealismo del propio Véron en L'esthétique. Véase Karatani, K., Origins of Modern Japanese Literature; Brett De Bary (Transl. \& Ed.), Duke University Press, Durham and London 1993, pp. 136-154 y MARRA, M., "A Voice of Resistance: Tsubouchi Shõyõ» en Modern Japanese Aesthetics. A Reader, Hawai'i University Press, Honolulu 1999, pp. 38-48. Para calibrar la influencia de las tesis de Véron en la posición de Tsubouchi, hay disponible la traducción de uno de sus textos: TsuBOUCHI, S., "What is Beauty?», en MARRA, Modern Japanese Aesthetics. A Reader, cit., pp. 48-64.

10 JACKSON, E., "The Metaphysics of Translation and the Origins of Symbolist Poetics in Meiji Japan», cit., p. 263. 
recordar, por más que sea algo evidente, que con el símbolo o el simbolizar $\mathrm{y}$, en definitiva, con todo re-presentar, se vuelve a presentar «algo» en forma lingüística o figurativa, no siendo posible la total equivalencia entre el nombre/ figura y la cosa. Sólo se aspira, aunque esto ya es mucho, a encontrarse con la analogía (o el «como si» kantiano) entre el «nombre» y la «cosa» nombrada.

La introducción del término «símbolo» que hace Nakae y el modo en el que se irá apreciando progresivamente en la producción literaria y filosófica japonesa durante el periodo Meiji y Taishõ (1912-1926) no debe hacernos olvidar que ya había, en tanto que forma convencional de comunicación, figuración y expresión, «simbolismo» en la filosofía y la literatura pre-modernas japonesas.

Teniendo presente siempre que el concepto «simbolismo» como tal no existe antes de la traducción de Nakae, lo que sí es posible es indicar que una parte del éxito de la poesía simbolista europea en el Japón moderno se debe, entre otras cosas, a la preexistencia, en palabras de Galik, de unas «relaciones consanguíneas» en los modos poéticos clásicos de la literatura de Asia Oriental (China, Japón y Corea). Es esta tradición poética clásica la que propicia la recepción a fines del siglo XIX y durante la primera década del siglo XX, del simbolismo ya establecido, retroactivamente, como movimiento literario europeo especialmente significativo en la poesía moderna francesa ${ }^{11}$. La consanguinidad que indica Galik refiere al tronco común de la expresividad poética y al uso compartido del simbolismo en la voz poética. Pues el simbolismo o uso de símbolos está presente en textos clásicos del pensamiento y la literatura china y japonesa al igual que lo encontramos en la antigüedad clásica griega desde la que derivamos nosotros su conceptualización moderna partiendo del vocablo griego symbolon.

De hecho, teniendo en cuenta la etimología del término empleado por Nakae, podemos decir que shõchõ y symbolon comparten, hasta cierto punto, una base común. En la Grecia antigua el vocablo symbolon se refería a la división en dos mitades de una tablilla que poseían las partes implicadas en un acuerdo ${ }^{12}$. Esa separación en dos partes que, reunidas nuevamente, recobraban y confirmaban la validez del pacto, pasó a utilizarse después como una fórmula de reconocimiento entre aquellos que querían mantener en secreto algunas prácticas religiosas o como convención para comunicar, mediante una señal, un mensaje. Progresivamente, el significado de «símbolo» se amplió y se convirtió en el que habitualmente entendemos hoy en la mayoría de las lenguas occidentales.

De igual modo parece que shõchõ incluye y recoge esa idea de reunir lo desunido. Si nos atenemos a la colección de poesía waka del Manyõshû (aprox. 777),

11 GaLIK, M., «Some Remarks on Symbolism in the Far Eastern Interliterary Process», en Mrugalla, A., Gössmann, H. (Eds.), Deutschsprachiger Japanologentag in Trier 1999, Vol. 2, Lit Verlag, Münster, 2001, p. 212.

12 Symons, A., The Symbolist Movement in Literature (1899), E. P. Dutton \& Co., New York 1908, p. 2. 
en esta obra clásica japonesa aparece la idea de kibutsu chinshi-器物沈思 ${ }^{13}$ que, en su literalidad, significa que los objetos externos, como receptáculos, pueden expresar los propios sentimientos. Es decir, que los objetos externos pueden reunir la interioridad con la exterioridad o, lo que es lo mismo, pueden ser susceptibles de reunir los dos planos de la Realidad que se nos muestran como desunidos.

La forma (por ejemplo, la palabra) acoge y reúne a la idea. Equivalente acción de juntar lo desunido está presente en el Yijing (Libro de las Mutaciones). Según indica Anne Cheng, el Yijing no se constituyó como fuente textual hasta un período tardío del pensamiento preimperial, en la última parte de los Reinos Combatientes (403-256 a.C) pasando a integrarse a los libros clásicos del pensamiento chino (Odas, Documentos, Ritos y Primaveras y Otoños) a principios de la dinastía Han (s. II a.C) ${ }^{14}$. Resumiendo en extremo alguna de las ideas que se encuentran en el Yijing y en todos los comentarios interpretativos que la obra ha suscitado y suscita, aquí sólo diremos que parece posible considerar un esbozo de esa idea compartida de símbolo como reunión de lo disgregado o separado: en la interpretación de los hexagramas del Yijing que propicia el mejor camino para la reunión del cielo (idea) y la tierra (forma), a nivel personal o político, favoreciendo una mejor comprensión y determinación reunificada, armónica, entre las fuerzas del mundo; o prestando atención a la prefiguración o imagen (xiang-象, en chino) —no otra cosa es también el símbolo que «figura» o «imagen»- de las consecuencias o resultados, a saber, de los efectos de una situación como concatenación o reunión de diversas circunstancias o actos, que el sujeto puede advertir al reflexionar sobre cualquier situación dada ${ }^{15} \mathrm{y}$ para decidir sobre sus acciones o decisiones futuras.

Esta parca indicación sobre la plausible base común entre el symbolon griego y el simbolismo en los textos clásicos del pensamiento y la literatura de China y Japón que se ha indicado, enlaza la genealogía de la moderna noción japonesa para «símbolo» de Nakae con la distinción, también moderna, de los principios cosmológicos unidos, según la escuela neoconfucianista de Su Shi (1037-1101), que Nishi separó al diferenciar claramente entre el ámbito de lo físico (butsuri-物理) y el de lo mental (shinri-心理) $)^{16}$.

Esta idea de unión/separación (y de los pares inmanente/trascedente, físico/ mental) parece que también casa con la utilización que hace Nakae del término shõchõ para traducir el concepto Erscheinung — apariencia, fenómeno- de los textos de Schopenhauer. En este caso, y a tenor de la explicación que aporta Jackson, Nakae, al traducir con la palabra «símbolo» la apariencia, Erscheinung, schopenhauriana y la idea del filósofo alemán de que la «apariencia»

13 GALIK, art. cit., p. 212.

14 Cheng, A., Historia del pensamiento chino. Traducción de Anne-Hèléne Suárez Girard, Edicions Bellaterra, Barcelona 2006, p. 233 y p. 235.

15 Ibídem, p. 245.

16 JACKsON, "The Metaphysics of Translation and the Origins of Symbolist Poetics in Meiji Japan», cit., p. 260 y p. 264. 
equivale al «ser» de cualquier objeto, recupera el sentido de la identidad entre el mundo y el modo en el que el mundo aparece ante nosotros. Es decir, reúne la apariencia del mundo con el «sentido» de dicha apariencia. Sea como fuere, parece claro que, al menos, con la adscripción del mismo término, shõchõ, a «símbolo» y «apariencia» en diferentes contextos textuales traducidos, se refuerza el trato ambivalente de la trascendencia de la filosofía occidental por parte de los pensadores del Japón Meiji ${ }^{17}$.

\section{LA RECEPCIÓN Y REPERCUSIÓN DEL MOVIMIENTO LITERARIO SIMBOLISTA EUROPEO EN LOS CÍRCULOS INTELECTUALES JAPONESES}

En Japón, el encuentro con el movimiento literario simbolista identificado con la poesía francesa de fines del siglo XIX, se produce gracias a la atención que el poeta y estudioso de literatura inglesa, UeDA Bin (1874-1916), le dedicó.

La difusión de la poesía simbolista se inicia cuando en el año 1897, Ueda elogia la figura del poeta Paul Verlaine (1844-1896) en su obituario «Paul Verlaine Muere» («Paul Verlaine Yuku») [«Paul Verlaine逝〈»] $]^{18}$. Pero es con la traducción y edición de poemas publicados en el año 1905 en el volumen titulado El sonido de la marea (Kaichõon) [海潮音] que la escritura poética simbolista, preconizada por Jean Moréas (1856-1910) ${ }^{19}$ como escuela, impacta a los poetas, filósofos e intelectuales japoneses.

Aunque Ueda incluye en El sonido de la marea a poetas que en nada se relacionan con la poética simbolista, como Shakespeare o Safo, es cierto que en una parte importante de su selección y traducción están representados algunos de los poetas y versos más significativos para entender el linaje de la poesía

17 Ibídem, p. 264.

18 JACKSON, E., Jr., "The Heresy of Meaning: Japanese Symbolist Poetry», Harvard Journal of Asiatic Studies, Vol. 51, No. 2 (Dec., 1991), p. 563.

19 Anagles, J., «The Heritage of Symbolism: The «Aesthetic» Style of Kitahara Hakushû and Murayama Kaita», PAJLS-Proceedings of the Association for Japanese Literary StudiesJapanese Poeticity and Narrativity Revisited, Vol. 4, Summer, 2003, p. 237. Jean MoréAs es el que da nombre a la escuela y clasifica la familiaridad «simbolista» de Verlaine, Mallarmé o Baudelaire en su artículo «A literary Manifesto» (1886). De hecho, Verlaine se refiere a Moréas y a su legitimación de la "escuela simbolista» (de la que él mismo se excluye) en algunas de sus notas y conferencias sobre el modo poético de su contemporaneidad: "No ignoráis que, aparentemente, estamos [los poetas] divididos en cuatro campos... Permitidme que diga, puesto que estamos en plena fraseología militar, que en cuatro cuerpos de ejército bajo el mando del mismo generalísimo: el Arte. Estos cuatro cuerpos de ejército son el Simbolismo, el Decadentismo, el grupo de los partidarios del verso libre y... los demás, entre los cuales estoy. Dejemos a un lado esa fastidiosa y cansada cuestión del Decadentismo y del Simbolismo. Lo cierto es que el Decadentismo se ha dispersado, y Moréas - el hombre absurdo es el que no cambia nunca-, Moréas él mismo ha disuelto la escuela simbolista para fundar la escuela románica» en «Conferencia acerca de los poetas contemporáneos» en VerLaINE, P., Los poetas malditos y otros textos (18841888). Traducción, prólogo y notas de Mauricio Bacarisse, Ediciones Júcar, Madrid 1987, p. 166. 
del diecinueve francesa, como «Canción de Otoño» («Chanson d'automne») de Verlaine ${ }^{20} \mathrm{o}$ «Suspiro» («Soupir») de Mallarmé ${ }^{11}$.

Si fuéramos estrictos en lo referente a los conceptos que los historiadores de la literatura manejan para clasificar los movimientos literarios, lo cierto es que estaríamos de acuerdo con la puntualización que hace Jackson al comentar que se podría hablar de la antología poética editada por Ueda más como una presentación de los Parnasianos, por su gusto por la poesía de Charles-MarieRené Leconte de Lisle (1818-1894), que como un marco de difusión representativo del movimiento simbolista ${ }^{22}$. No obstante, esta disquisición no la hicieron los lectores japoneses que recibieron y leyeron la antología de Ueda como una colección de poesía simbolista y así la entendieron.

Si además tenemos en cuenta que poco después de la antología de Ueda, en 1907, el escritor Iwano Hõmei (1873-1920) traduce la obra de Arthur Symons, El Movimiento Simbolista en Literatura (Symbolist Movement in Literature) (1899) ${ }^{23}$ donde se incluyen y prefiguran bajo el paraguas del «movimiento simbolista» a escritores, algunos entre sí muy distantes productiva y estilísticamente, como Gérard de Nerval (1808-1855), Villiers de l'Isle-Adam (1838-1889), Arthur Rimbaud (1854-1891), Verlaine, Jules Laforgue (18601887), Mallarmé, Joris Karl Huysmans (1848-1907) y Maurice Maeterlinck (1862-1949), el suelo teórico para el surgimiento de jóvenes poetas japoneses inspirados por el movimiento simbolista estaba más que preparado.

A la luz de la radicalmente moderna expresividad poética que les ofrecía el simbolismo, destaca la colección de poemas de Kitahara Hakushû (18851942), Herejía (Jashûmon) [邪宗門] (1909)24. Kitahara fue miembro activo de la «Sociedad Pan» («Pan no Kai») [パンの会] que aglutinaba a diversos artistas visuales y poetas ${ }^{25}$, emulaba en sus reuniones las discusiones sobre arte y literatura en los cafés franceses del diecinueve y en las que participaron figuras destacadas de la literatura como el mismo Ueda o el novelista, conocido en lengua castellana principalmente por su breve ensayo El elogio de la sombra (Inei Raisan) [陰影礼賛] (1933), TANIZAKI Jun'ichirõ (1886-1965) ${ }^{26}$. Ese movimiento

20 Véase traducción al castellano en Verlaine, P., Poesía. Introducción, traducción en verso y notas de Carlos Pujol, Editorial Planeta, Barcelona 1992, p. 11.

21 Véase la edición bilingüe del poema así como el estudio crítico sobre el poeta y su obra en Gómez Bedate, P., Mallarmé, Ediciones Júcar, Madrid 1985, pp. 172-175.

22 JACKsOn, E., Jr. «The Metaphysics of Translation and the Origins of Symbolist Poetics in Meiji Japan», cit., p. 265.

23 Ibídem, p. 264.

24 Hay versión en línea disponible de esta colección de poemas en la librería digital Aozora Bunko. Véase URL: http://www.aozora.gr.jp/cards/000106/files/4850_13918.html (Última consulta: 29 Agosto del 2011).

25 Como los promotores de la revista de arte y poesía, Hõsun (que se podría traducir como «sol cuadrado» o «mente propia») [方寸]: Yамамоте, K. (1882-1946), IshiI, H. (1882-1958) o Morita, T. (1881-1933) o el propio Kitahara. Véase, ANGLES, art. cit., pp. 238-239.

26 Tanizaki entroncado, además, con la figura de Edgar Allan Poe (1809-1849), cuya influencia se deja sentir en el sentido de lo grotesco presente en muchos de los cuentos y 
primero pasaría a autoidenficarse más tarde con el nombre de «Escuela Estética» («Tanbiha») [耽美派].

Es significativa la teorización de Kitahara sobre la modernidad poética que aparece en Herejía donde propugna que la fuerza vital de la poesía no radica en la desnuda explicación descriptiva de fenómenos, sino en la «intimación», es decir, en la correspondencia entre el ánimo personal del poeta, lo que le rodea y el poema que escribe. En el texto introductorio de esta colección de poemas, Kitahara aporta una valiosa redefinición que acota lo que él entiende por «símbolo» como herramienta de la creatividad poética:

The life force of a poem is found in intimation, not in simple explanations of phenomena. The poet addresses the faint, indistinc sobs of the spirit that arise amidst the limitless trembling of emotion that cannot be fully expressed through writing or speech. He is enamored with the pleasure of barely audible music, and he takes pride in the grief in his own impressions. Isn't this the fundamental purpose of the symbol? We face the mysterious, we rejoice in visions, and yearn for the red putrefying decadence. Alas! Even in our dreams, we, the disciples of a modern heretical faith, cannot forget the laments of marble sobbing in the pale, white light of the moon. (... ${ }^{27}$.

La fuerza vital de un poema se encuentra en la intimación, no en las simples explicaciones de los fenómenos. El poeta se dirige a los pálidos, indistintos sollozos del espíritu que surgen de entre el ilimitado estremecimiento de la emoción que no puede expresarse completamente con la escritura o el habla. Él está enamorado del placer de la música apenas audible y se enorgullece en la pesadumbre de sus propias impresiones. ¿No es éste el propósito del símbolo? Miramos hacia lo misterioso, nos regocijamos en visiones y anhelamos la roja y pútrida decadencia. ¡Ay! Incluso en nuestros sueños, nosotros, los discípulos de la moderna fe herética, no podemos olvidar los lamentos del mármol que solloza en la pálida y blanca luz de la luna. (...).

Aunque es algo que pasan por alto los comentaristas de la obra de Kitahara que se han consultado, más centrados en cuestiones relativas al estilo

novelas de su primera etapa narrativa (1910-1928). Es también B. Ueda, en el año 1902, el que introdujo la figura de Poe a los lectores japoneses apuntando la filiación directa del americano con el impulso y desarrollo de la poesía francesa simbolista a partir de Baudelaire quien tradujo, como es sabido, las obras de Poe al francés y reconoce en él la inspiración para su forma poética que otros seguirían después. A poco que se conozca la obra de Poe y la de Baudelaire, no sorprende que en el año 1946 T. S. Eliot explicitara ese linaje común que va de Poe a Valéry en la construcción de la poesía moderna. Véase respecto a Tanizaki y Poe: LiPPIT, Noriko Mizuta, «The Grotesque and the Quest for Supernal Beauty», Comparative Literature, Vol. 29, No. 3 (Summer, 1977), pp. 221-240. El ensayo de Eliot, «The Unity of European Culture» (1946) puede encontrarse traducido al castellano en la recopilación de ensayos de PoE, Baudelaire, Mallarmé, Valéry y Eliot aparecidos recientemente en el volumen Matemática tiniebla. Genealogía de la poesía moderna. Idea, selección y prólogo de Antoni Marí, traducción de Miguel Casado y Jordi Doce, Galaxia Gutenberg-Círculo de Lectores, Madrid 2011, pp. 400-415.

27 Véase traducción del texto completo de la introducción a su obra Herejía (Jashûmon) [邪宗門] donde Kitahara indica los principios teóricos de la nueva expresividad poética en ANGLES, art. cit., pp. 239-240. Cursiva añadida. 
o el análisis crítico de sus poemas, desde mi punto de vista, en el texto aquí parcialmente citado es posible leer una dialéctica compleja entre modernidad y tradición. Pues, para Kitahara, el «símbolo» en poesía e, implícitamente, la influencia simbolista europea, ayudarán a dar un vuelco a la expresión poética japonesa en su proceso de modernización y de experimentación de nuevas formas. La nueva poesía y sus poetas acogerán, apreciando las armas expresivas de la poesía simbolista europea, algunos rasgos que les vienen dados del patrón «occidental». Por eso serán «discípulos de la moderna fe herética». Pero el poeta japonés no podrá desterrar de sí su voz inherente, su propio patrón, que recibe de su amplísima tradición poética japonesa: «no podemos olvidar los lamentos del mármol que solloza en la pálida y blanca luz de la luna».

La yuxtaposición de las imágenes de la modernidad poética occidental y esas otras propias de la tradición poética japonesa son un rasgo constante que determina, a mi entender, algunos de los poemas de Kitahara en Herejía. Más allá del uso de imágenes sinestésicas, la interpenetración de lo visual, lo táctil o lo sonoro y la rotura consciente de la lógica y el orden perceptivo, al igual que encontramos en Baudelaire, Verlaine o Rimbaud, es en esa identificación consciente de Kitahara como "discípulo» de la religión herética (pues la palabra

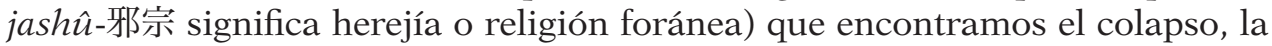
contradicción interna frente a la alteridad. Alteridad no sólo frente a las influyentes formas de la poesía francesa del diecinueve difundidas y apreciadas por los jóvenes poetas japoneses, sino también respecto al proceso de revolución, transformación y cambio incesantes de las primeras décadas del siglo XX en Japón.

Ejemplo bellísimo de ese desasosiego del poeta que vive en el interior de los cambios sociales que se suceden y que contempla y expresa, es el poema incluido en la obra, "La canción secreta de la herejía» («Jashûmonhikyoku») [《邪宗門秘曲》]. En sus versos, plagados de descripciones que juegan con la sinestesia, encontramos diversas representaciones de sensaciones sensoriales y atmosféricas que buscan corresponder al estado emotivo del poeta y que intiman su individualidad con el ruido de unas palabras que no entiende, heréticas, extranjeras, que se entremezclan en el nuevo mundo en el que vive. En el poema, la traducción de las palabras extranjeras es fonética aunque no mediante el uso común del silabario katakana. Kitahara realiza la traducción fonética mediante el uso de kanji con igual pronunciación que las palabras extranjeras, algo que potencia aún más el ruido, la sensación de soledad ante la incomprensión del puro sonido ininteligible. Así, en los versos el poeta refiere, entre otras cosas, al «dios cristiano» (kirishitan deusu-切支丹でうす); a los «barcos negros» y el «capitán» que recuerdan a los buques del Comodoro Perry a su llegada a la bahía de Tokio en 1853 (kurofune no kahitan-黒船の加比丹); al «vidro» de colores rojizos portugués usado en las ventanas (iroakaki biidoro-色 赤きびいどろ); los claveles, «anjebier», holandeses (anjabeiiru-あんじやべいいる); la ropa portuguesa de «San Tomé» (santomejima-栈留縞); el licor «arak» holandés (araki-阿刺吉); el «vino tinto» portugués o español (chinta no shu-珍の 酒); la enunciación sánscrita repetida por los buddhistas en plena meditación, 
«dharani» (darani-陀羅尼); la «cruz» (kurusu-聖磔); el «paraíso» (haraiso 波羅 蔁僧) o el «padre» celestial (bateren-伴天連) ${ }^{28}$. Todo ello no es otra cosa que un intento poético por apreciar y recoger lo que difícilmente puede ser expresado por las palabras — cierta alienación o alteridad esencial.

Para finalizar esta parte, indicar, a modo de compleción de la contextualización sobre la recepción y repercusión del movimiento literario simbolista en los círculos intelectuales japoneses, que la producción poética de Kitahara no es única ni excepcional. Otros nombres importantes deben ser tenidos en cuenta a la hora de referir al movimiento simbolista japonés. Figuras como la del pintor y poeta MuRAYAMA Kaita (1896-1919), fuertemente influido por la obra de Kitahara y que produce su obra poética en un muy breve lapso de tiempo, desde 1912 hasta su muerte por tuberculosis; Miкi Rõfu (1889-1964) o el poeta KANBARA Ariake (1875-1952), en cuya etapa de filiación simbolista es fácilmente reconocible el gran alcance que tuvieron las primeras obras traducidas y difusoras de la poesía simbolista.

Kanbara admira el fondo poético de Leconte de Lisle o Huysmans (introducidas, como hemos visto, con las antologías poéticas traducidas por Ueda e Iwano) pero no se complace con la simple exploración y utilización formal de la moderna poesía. Se fija muy especialmente en el fondo especulativo presente en la poesía simbolista que aparece como una escuela poética que abre la posibilidad de explorar la interrelación entre la reflexión filosófica (en Kanbara, fuertemente buddhista) y la poesía. Eso sí, una poesía concebida más allá de ser un mero marco estilístico o una simple poesis productiva, y, más acá, como una oportunidad nueva para las cadenas propias y connaturales a la representación lingüística.

Para Kanbara se trata, más bien, de apreciar que con esa nueva forma poética es posible traspasar todo aquello que en rigor es inexpresable, que no se deja atrapar con las palabras. La expresión poética simbolista se lanza a experimentar con la ruptura de la lógica, con la superación del horizonte del lenguaje y del tope del sentido y el significado, para poder ir más allá de los límites estrictos del lenguaje. El traspasar la lógica del lenguaje entronca con las ideas que se veían con anterioridad, a saber: con la conceptualización de símbolo que preconizaba, como vimos, la posibilidad de asociación, reunión, reciprocidad entre el yo y el mundo externo. Así lo expresa Kanbara en la siguiente cita con la que concluir este apartado:

Symbolist poetry is not a limited, arrogant intellectual poetry. Modern literature offers a profound experience in those works in which it escapes human-centered thought. When one examines the mutual relationships between the «self» and the phenomena of the external world, and the «self» and the power of a more expansive nature immersed within the phenomena, the undulations between the inner and outer worlds multiply, and one can truly

28 Hay traducción en inglés del poema en JACKson, E., Jr. «The Heresy of Meaning: Japanese Symbolist Poetry», cit., pp. 566-567. 
participate in the kaleidoscopic tumult of life. Beyond this there is nothing, and there is essentially no other realm [for modern poetry ${ }^{29}$.

La poesía simbolista no es una poesía intelectual limitada y arrogante. La literatura moderna ofrece una experiencia profunda en aquellos trabajos en los que escapa de un pensamiento ego-centrista. Cuando se examinan las relaciones mutuas entre el «yo» y los fenómenos del mundo externo y entre el "yo» y el poder de una naturaleza más expansiva inmersa en el interior de los fenómenos, las ondulaciones entre los mundos interior y exterior se multiplican. Uno puede así participar verdaderamente del caleidoscópico tumulto de la vida. Más allá de esto no hay nada. Esencialmente no hay ningún otro camino [para la poesía moderna].

4. El conocimiento del Simbolismo literario POR PARTE DE Nishida: SU CONTACto CON UEDA EN LA Universidad dE KYOto

Sabemos por la biografía intelectual que Yusa Michiko publicó sobre NisHidA Kitarõ que éste coincidió con UEDA Bin, artífice, como se ha visto, de la introducción y difusión de la poesía simbolista en Japón. Nishida y Ueda se encuentran en el departamento de Humanidades de la entonces Universidad Imperial de Kyoto. El centro universitario dedicado al estudio de las Humanidades se funda en el año 1906 y es justo en los años en los que ambos coinciden, inaugurada la década de 1910, que en el centro universitario se concentran muchos de los intelectuales que serían la avanzadilla del país en diversos ámbitos de estudio (filosofía, psicología, historia, sociología, literatura, etc.) ${ }^{30}$.

Es entonces, cuando Nishida comienza su carrera como profesor asistente en la Universidad de Kyoto encargado de un curso introductorio de Filosofía (tetsugaku gairon-哲学概論) y otro especializado en cuestiones de ética (rinrigaku-倫理学), que mantiene un contacto diario y, por tanto, una interlocución directa, con dos colegas, uno de ellos, el propio Ueda y, el otro, KuwAKI Gen'yoku $(1874-1946)^{31}$. Con toda seguridad, en sus intercambios y diálogos con ellos se alimenta y enriquece una parte importante de la atención que muestra Nishida en dos ámbitos. Uno, la filosofía de Kant, de la que es gran conocedor y especialista Kuwaki y que es un referente ineludible a la hora de estudiar las obras de Nishida. La otra, a través de su amistad con Ueda, la literatura europea y, en lo que aquí nos concierne, el simbolismo. Por tanto, en lo tocante al conocimiento de los poetas simbolistas es altamente probable que conociera de primera mano la tarea de difusión de Ueda. Y, sin dudas, a tenor de las citaciones y

29 Kanbara citado en Ibídem, p. 584.

30 Yusa, M., Zen and Philosophy. An Intellectual biography of Nishida Kitarõ, Hawai'i University Press, Honolulu 2002, p. 119.

31 Ibídem, p. 122. En sus cartas, Nishida se refiere a los dos como «Freidenker» - librepensadores. 
referencias que hace, los leyó y sobre ellos puso su interés filosófico en diversas ocasiones. Sobre esas citaciones y referencias en el interior de su obra filosófica centraremos la atención para llegar a encontrar, en la medida de lo posible, las razones que hay tras la introducción de dichas referencias y el sentido que acogen en contacto con sus propias ideas filosóficas.

\section{ACOTACIONES SOBRE EL TIPO DE SIMBOLISMO PRESENTE EN LA PRIMERA ETAPA DE NISHIDA}

Antes de pasar al proceso hermenéutico de algunos textos de Nishida significativos para nuestro objeto de estudio, es necesario aclarar a qué tipo de simbolismo parece que nos remite el filósofo.

El simbolismo, como corriente inserta en la filosofía, es un ámbito con muy diversas texturas y derivaciones teóricas. Para empezar, porque es frecuente confundir el uso de los términos «símbolo» o «signo» que, en muchas ocasiones, funcionan como conceptos sinónimos. Por ejemplo, se da esta sinonimia en el interior de algunos sistemas filosóficos que influyeron en mayor o menor medida a Nishida. Así sucede, por ejemplo, si consideramos la filosofía de A. Meinong (1853-1920) al que Nishida leyó y al que menciona en su primera etapa de producción filosófica, cuando está más imbuido en corrientes relacionadas con la psicología, la epistemología, las matemáticas y fuertemente interesado en el estudio del neokantismo. Valga mencionar que a Meinong lo cita cuando se cuestiona sobre la idea de objeto, haciendo uso de la teoría de los objetos de éste y, por extensión, del objetivismo lógico de Bolzano y la primera formulación fenomenológica de Husserl.

La ambigüedad inherente al par de conceptos signo/símbolo es sencilla de explicar aunque difícil de resolver en tanto se profundice en la lectura y estudio de algunas obras filosóficas como las del mismo Nishida. No entraremos aquí a discutir esta cuestión, pero sí que podemos mencionar que desde la habitual diferenciación entre "signo», en tanto que señal natural, y «símbolo», como señal convencional, no siempre es posible mantenerse en el marco de esa diferencia entre natural y convencional. Alternativamente un signo puede ser un símbolo o al revés dependiendo del contexto. Será el contexto el que acabará por inclinar la balanza hacia un determinado sentido último de aquello que se ha comunicado.

Teniendo en cuenta el complicado estilo filosófico de Nishida y su forma siempre sucinta y nada sistemática a la hora de citar las fuentes que utiliza, tampoco en su caso resulta fácil identificar a qué tipo de simbolismo se refiere ni clasificarlo herméticamente entre lo que sería, por ejemplo, un simbolismo específico (religioso o artístico, por ejemplo), según la clasificación de Ferrater Mora $^{32}$, o bien un simbolismo más estrictamente «filosófico». Por ejemplo, en el

32 Ferrater Mora, J., Diccionario de Filosofía, reimpresión Ariel, Barcelona 2004, p. 3282. 
de la línea de pensamiento sostenida en los años 1920 por Ernst Cassirer (18741945), al que también lee Nishida en el contexto de su interés por la Escuela de Marburgo, y cuya antropología filosófica y su concepción del hombre como animal symbolicum ${ }^{33}$ ha derivado en muchas líneas de pensamiento contemporáneo.

Nuevamente es el contexto el que determinará el sentido del simbolismo en las ocasiones en las que encontraremos el uso del concepto «símbolo» o bien la referencia a la escuela literaria simbolista en los ensayos nishidianos. Así lo haremos, indicando, siempre que sea posible, si lo que encontramos es una referencia al símbolo como elemento artístico, como mero concepto remitido a la reflexión lingüística o bien como cuestión relacionada con el simbolismo filosófico. Sí que se puede adelantar ahora que habrá mucho de simbolismo artístico (en la pura referencia a los poetas simbolistas y en general en lo referente a cuestiones de estética y/o filosofía del arte) y también una amplia correlación o igualación entre el «símbolo» en su potencia expresiva poética y filosófica. Lo que sí es claro es que el concepto se tantea como noción expresiva propicia para conjugarse con y reforzar determinados argumentos filosóficos.

\section{Filosofía y POESÍA EMPARENTAdAS: El USO FILOSÓFICO DEL SIMBOLISMO EN NishidA KITARÕ}

Teniendo en cuenta estas dificultades connaturales al método filosófico y también a la habitual asistematicidad de Nishida, ahora ya es posible pasar a analizar algunas referencias textuales específicas y significativas para avanzar en el cuestionar sobre el uso filosófico del simbolismo en las primeras obras del japonés.

El primer texto al que se hará referencia pertenece a su obra Intuición y reflexión en la autoconciencia (1917). Ésta, su segunda obra publicada tras el éxito en los círculos filosóficos de Japón de la primera, Estudio sobre el Bien (Zen no Kenkŷ̂) [善の研究] (1911), surge y se construye alrededor de toda una serie de cuestiones que le parecían al filósofo que no habían quedado desarrolladas completamente o se habían mostrado o incoherentes o insuficientes en su primera exposición filosófica. Sucede, por tanto, que esta obra está en diálogo constante con la primera y que, si se conoce bien la primera, se facilita la comprensión de muchas de las ideas repensadas en la segunda. Porque es, en muchos aspectos, una enmienda de conceptos e ideas que el pensador esboza en Estudio sobre el Bien y que revisa y repiensa.

En Estudio sobre el Bien, el concepto central sobre el que pivota la obra es el de experiencia pura (junsui keiken-純粋 経験). A fin de superar algunas de las limitaciones inherentes a dicho concepto, Nishida lo reconsidera y cree

33 Concepto delimitado en su obra Filosofía de las formas simbólicas en 3 volúmenes $(1923 ; 1925 ; 1929)$. 
que su reformulación como autoconciencia (jikaku-自覚) ${ }^{34}$ puede funcionar de una manera más idónea. La noción de experiencia pura (junsui keiken-純粋 経験)/experiencia directa (chokusetsu keiken-直接 経験) había dejado muchos espacios en blanco y adolecía de muchas carencias en el interior de su primer sistema.

En Estudio sobre el Bien no se resolvía, sino, más bien, se enfatizaba, la prevalencia del componente psicologicista clave en la delimitación del concepto de experiencia pura. Esto comportaba que todo el sistema pareciera arribar finalmente a la afirmación de una pura intuición intelectual y un solipsismo que, entre otras cosas, obviaba la función y centralidad de la función reflexiva ${ }^{35}$.

Queriendo redefinir y pulir la estrategia ya encaminada en su primer ensayo, Nishida persigue encontrar con el concepto de autoconciencia un principio unitario y originario capaz de eliminar todo dualismo epistemológico y, en consecuencia, ontológico y metafísico.

A nivel ontológico, una asunción básica y constante de Nishida es la de sostener que la Realidad es unitaria y que tal unidad se sostiene sobre la unificación posible de todos los principios que aparentemente se nos figuran como opuestos. A nivel epistemológico, el filósofo entiende posible acceder al

34 En referencia al término japonés que designa lo que aquí se denomina «autoconciencia», hay que mencionar que el vocablo Jikaku-自覚 aparece traducido principalmente, en el contexto de obras filosóficas, de dos maneras distintas: como «autoconciencia» o como «auto-despertar». Asimismo, otros investigadores expertos en la obra de Nishida como Zavala, A. J. optan por traducir la noción «jikaku» por «autopercepción». Respecto a la explicación a la traducción del término como «autodespertar» puede consultarse TREMBLAY, J., «Introduction de la traductrice», en Nishida, K., L'Eveil à soi. Trad. Tremblay, J., CNRS, París 2003, pp. 9-51. Es significativa la puntualización que hace un gran conocedor de la filosofía japonesa como Heisig, J. W. que reivindica la diferencia significante del término japonés al optar él por traducir este término como "autodespertar» (y, en inglés, "self-awareness») defendiendo que Nishida lo utiliza con el claro propósito de distanciarse de lo que en Occidente se ha entendido corrientemente por autoconciencia. Véase HeIsig, J. W., Filósofos de la Nada. Un ensayo sobre la Escuela de Kioto, Editorial Herder, Barcelona 2002, pp. 79-80. En inglés generalmente se ha optado por traducir el término como "autoconciencia» (selfconsciousness) y así aparece en la edición de la obra traducida al inglés. En castellano, encontramos que otro gran conocedor de la filosofía de Nishida, K. y de la lengua japonesa, González Valles, J., traduce el término por "autoconciencia». Valorando y apreciando las puntualizaciones expuestas por los expertos en la obra nishidiana, aquí optaremos por traducir el término como «autoconciencia».

35 En Mayo-Junio de 1912, poco tiempo después de publicada la obra de Nishida (1911), aparece la reseña escrita por TAKAHASHI, T. con el título «Hechos y significados de los fenómenos de conciencia» en la revista Revista de Filosofía (Tetsugaku Zasshi) de la Universidad Imperial de Tokio. Aunque Takahashi alaba la importancia de la reflexión filosófica llevada a cabo por Nishida, le critica duramente la ambigüedad de la noción de experiencia y conciencia pura. Incapaz de encontrar en el ensayo de Nishida un fundamento sólido para definir qué es la experiencia pura, este graduado en filosofía sostiene que la noción peca no sólo de psicologismo, sino también de misticismo. La experiencia pura, según el punto de vista de Takahashi, parece ser otro modo de hablar de un estado de iluminación espiritual que puede convertirse en un sistema auto-referencial, incapaz de salir de las mismas dicotomías de las que pretende zafarse (pura/impura, hechos/significados, etc.). Véase Yusa, op. cit., pp. 128-129. 
conocimiento de esa Realidad unitaria y originaria, aún no disgregada o diferenciada. De su postura se deduce que cualquier sostenimiento del edificio filosófico sobre diferentes pares duales no hace otra cosa que fragmentar la Realidad y llevarnos a un erróneo conocimiento sobre ella. Es precisamente para fijar los cimientos de un sistema epistemológico y metafísico resguardado de los errores del dualismo que piensa en el sistema de la autoconciencia. Y, en primer lugar, tratará de demostrar cómo se produce el vínculo de las dos funciones que definen la actividad de la conciencia: la intuición (chokkan-直感) y la reflexión (hansei-反省) ${ }^{36}$.

Nishida define intuición y reflexión en las secciones iniciales de la obra englobadas bajo el epígrafe «Autoconciencia: Algunos problemas» ( Jikaku no igishuju no gimon») [《覚の意義. 種々の疑問》 $]^{37}$. Allí delimita las funciones de la intuición y la reflexión como sigue:

- Intuición: es la conciencia de la progresión intacta/ininterrumpida de la Realidad tal y como ésta es; conciencia donde sujeto y objeto aún no se han dividido y donde el sujeto que conoce y aquello (objeto) que es conocido son una misma cosa.

- Reflexión: es la conciencia que, estando fuera (abstraída) de la progresión intacta de la Realidad, se voltea ${ }^{38}$ sobre sí y la (se) mira ${ }^{39}$.

En suma, explicita las dos facultades que componen una misma conciencia que, a su vez, forma parte de la Realidad tal y como ésta es. Realidad ya sea considerada como un todo indiferenciado (con la intuición) o bien como una unidad desde la que se han abstraído e individuado sus componentes (con la reflexión), entre otras cosas, para poder ser conocidos. No nos habla de dos tipos de conciencias, sino de una única conciencia pero vista desde diferentes perspectivas.

36 Se puede consultar en relación a este tema STEvens, B., Invitación a la filosofía japonesa. En torno a Nishida. Traducción de José Miguel Marcén, Edicions Bellaterra, Barcelona 2008, pp. 126-127.

37 NishIDA, Intuition and Reflection in Self-consciousness, cit., pp. 3-12 (NKZ2-pp. 15-30). En la serie de volúmenes de las obras completas de Nishida antes citada bibliográficamente la obra Intuición y reflexión en la autoconciencia se encuentra en el volumen 2. Citaremos la edición inglesa de la obra poniendo entre paréntesis tras la página de la citación de esta versión la paginación correspondiente a la obra en japonés con las siglas NKZ2.

38 El uso aquí del verbo voltear no es extraño a la filosofía y en concreto a la reflexión

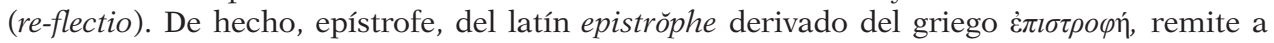
«vuelta» y fue utilizado por los neoplatónicos (Plotino, por ejemplo) para describir propiamente ese proceso de vuelta sobre sí de los entes racionales que comúnmente denominamos reflexión. Ahora, no obstante, en una de sus acepciones se utiliza como sinónimo de la figura retórica de la "conversión», a saber, la figura consistente en emplear una misma palabra al fin de dos o más cláusulas o miembros del período. Véase MARBACK, R. C., «Rethinking Plato's Legacy: Neoplatonic Readings of Plato's Sophist», Rhetoric Review, Vol. 13, No. 1 (Autumn, 1994), pp. 30-49 y Henrich, D., Between Kant and Hegel. Lectures on German Idealism, PacinI, D. S. (Ed.), Harvard University Press, Cambridge-London 2003, pp. 247-248.

39 NIsHIDA, Intuition and Reflection in Self-consciousness; cit., p. 3 (NKZ2-p. 15). 
La autoconciencia sería el lugar en el que las dos funciones, intuición y reflexión, coinciden y se correlacionan, propiciando que sea conocida y reconocida la identidad radical y unitaria de la Realidad, empezando por la del propio sujeto particular.

La detallada explicación del concepto de autoconciencia y del sistema filosófico que Nishida deriva a partir de él, son cuestiones sobre las que aquí no se puede entrar en más detalles pues el objetivo de este trabajo es mucho más concreto y versa sobre el uso del simbolismo por parte del filósofo. Así, en lo que a este trabajo respecta, las indicaciones dadas antes sobre la autoconciencia, la intuición y la reflexión deberán bastar como marco conceptual simple y en extremo abreviado pero a tener en cuenta en relación a las citaciones textuales concretas que se verán.

Dicho esto, fijémonos ahora en la primera referencia textual en la que aparece el cuestionarse nishidiano sobre el simbolismo. La primera formulación en la que Nishida introduce el concepto de símbolo nos acerca a la dificultosa diferenciación entre signo y símbolo. Ahora bien, no es la diferencia entre signo y símbolo lo que quiere aclarar el filósofo. La introducción del discurso sobre el signo y el símbolo le sirven pero no como problema por sí mismo, sino como analogía idónea para esclarecer otra cuestión que le preocupa resolver y que tiene que ver directamente con la subjetividad y la expresión: el examen de la relación entre significado (imi-意味) y existencia (sonzai-存在).

Si recordamos el marco conceptual que definía la traducción de «símbolo», shõchõ, y lo que en definitiva comportaba para las bases del pensamiento japonés, a saber, la introducción de toda una serie de dualidades (inmanente/ trascendente, físico/mental, etc.), entre ellas estaría una sobre la que se cuestiona Nishida en Intuición y reflexión en la autoconciencia: significado/existencia. Disponemos, así del primer marco conceptual sobre el que introduce la discusión en torno al «símbolo» y el «signo» (fuchou-符牒).

Porque, tal y como enuncia Nishida en la primera parte de la obra, si queremos aclarar cómo es posible decir de cierta cosa que verdaderamente existe en tanto disponemos de su significado, la cosa debe existir antes puesto que no podemos derivar su existencia del significado ${ }^{40} \mathrm{o}$, de hacerlo, lo haríamos en el interior de una pura paradoja. Se trata, por tanto, de encontrar el punto en el que se da la unión entre existencia y significado y, si es posible, mantener esa relación de identidad entre lo existente y lo que para nosotros significa eso existente, sin caer en aporías.

Es en este contexto que Nishida encuentra útil mirar hacia los signos y símbolos si, con su mención, se facilita entender mejor la relación de identidad entre existencia y significado.

Esta es la trascripción del texto que a continuación se va a analizar:

Podemos empezar nuestro examen de la relación entre significado y existencia prestando atención a los signos y los símbolos sobre los que

$40 \quad$ Ibídem, p. 12 (NKZ2-p. 30). 
normalmente se piensa que conectan estos dos ámbitos. En los signos, las palabras, por ejemplo, no hay relación interna entre el carácter de la instancia o la naturaleza de la cosa indicada; las palabras indican significados al igual que el signo de la cruz indica Cristianismo, en virtud de una asociación extrínseca entre el signo y lo significado. En el caso de los símbolos, por ejemplo, el lirio representando la pureza, encontramos un grado de relación interna entre el carácter del símbolo y el significado que designa. Las dos cosas se mezclan indisociablemente en una única forma significante, como base de la experiencia inmediata; todas las relaciones que la obra de arte tiene con los significados que traspasa son de este orden. Sin embargo, incluso la relación simbólica no es puramente intrínseca: estamos inclinados a decir que el lirio contiene o evoca el sentimiento de pureza, pero este sentimiento debería estar justamente asociado con otro símbolo. No hay vínculo entre las dos cosas; el sentimiento se une extrínsecamente al símbolo ${ }^{41}$.

En principio parece que los signos y los símbolos permiten unir el significado y la existencia y es por ello que el filósofo centra su atención en ellos. Para Nishida, las palabras ejemplifican en qué consisten los signos. Lo que particulariza a los signos es que éstos no se relacionan de manera directa con el hecho indicado o la naturaleza de la cosa nombrada. Señalan un determinado significado, según nos dice, al igual que el signo de la cruz indica "cristianismo»: no hay nada en la cruz que, intrínsecamente, se relacione con el cristianismo. Nosotros «creamos» a posteriori o llenamos de sentido el signo, que no tiene previamente el significado que le adscribimos intencional y regulativamente. Así pues, el signo y lo significado se asocian extrínsecamente y no porque haya algo interno y propio que los asocie indefectiblemente.

Como se aprecia en la cita textual, Nishida titubea a la hora de circunscribir en qué consiste el símbolo. Al principio postula que en el caso de los símbolos sí que es posible, a diferencia de lo que sucede en los signos, encontrar un grado de relación interna entre el carácter del símbolo y el significado que designa. Así, se da forma a una única asociación entre significante y significado que podemos conocer y reconocer (experiencialmente) de manera inmediata. Para ejemplificar la difícil sostenibilidad de esta idea, sin duda, problemática, Nishida se refiere a la relación simbólica entre el lirio y la pureza.

En verdad, con este ejemplo no hay una clara diferencia entre signo y símbolo puesto que más o menos encontramos la misma situación cuando se adscribe "cristianismo» a la señal de la cruz que cuando al lirio le adscribimos la idea de «pureza». En ambos casos, la adscripción de significado se realiza extrínsecamente y mediante un proceso a posteriori — no otra cosa sucede con la idea de pureza que requiere de otros referentes previos (entre otros, un significado previo de qué es aquello que entendemos por «puro»o «pureza») para posteriormente (extrínsecamente) encontrar que el lirio se corresponde con tal idea de pureza. Asociación que, por otra parte, antes ya debería estar determinada y definida aunque fuera vagamente.

\footnotetext{
41 Ibídem, p. 13 (NKZ2-p. 31). Cursiva añadida.
} 
Nishida es plenamente consciente de la limitación de su explicación y, especialmente, del ejemplo que emplea para definir símbolo y de la cadena de evocaciones o asociaciones necesarias previamente hasta poder llegar a la ecuación entre lirio y pureza, su ejemplo. La sintonía o identidad entre lo existente (el lirio) y su significado (pureza) desde el punto de vista del símbolo no es en absoluto evidente y, por tanto, no es posible sostener que en la relación simbólica se expresa claramente la relación intrínseca entre el objeto existente y su significado. Lo que hay, como mucho, y según puntualiza Nishida, es una «inclinación» (indefinida) a decir que un lirio «contiene» o «evoca»el sentimiento de pureza. Pero dicho sentimiento debe tener su causa primera en otra asociación simbólica. Esto comporta que el sentimiento (que es lo que se expresa en la identidad entre lirio y pureza) se adiciona extrínsecamente al mismo sentimiento. Es, por tanto, posterior, fruto de la expresividad que no es otra cosa que un acto hacia fuera, exterior, como lo es cualquier acto lingüístico. El acto lingüístico conforma en palabras lo que, en rigor, parece ir más allá del posible canon cerrado de cualquier vocablo o de la palabra concreta con la que referimos al objeto («lirio» para referirnos a la flor) y sobre el que queremos mostrar la relación intrínseca con una idea o significado («pureza»). Idea, por otro lado, que también acoge la forma de una palabra por más que surja desde un sentimiento (per se interno) informe, indefinible lingüísticamente de un modo completo y absoluto.

Hasta aquí, la aplicación de la diferencia entre signo y símbolo lejos de haber aclarado la conjunción entre significado y existencia lo que hace es complicarla. Como reconoce Nishida unas líneas más adelante, partir del signo es concebir el vínculo entre significado y existencia en tanto arbitrario o accidental (nuestra adscripción de un significado a una palabra). Partir del símbolo tampoco ayuda demasiado: aunque nos remite a un posible fondo de relación causal necesaria entre la cosa y el significado, nos obliga a preguntarnos por la cadena causal, o sea, sobre qué es lo que origina tal necesidad por la cual estamos inclinados a sentir y decir que el «lirio» denota "pureza» ${ }^{42}$. Esto nos encierra, desde un punto de vista en primera instancia únicamente subjetivo, en el solipsismo: la causa final será mi particular sentimiento, yo mismo que siento que el lirio remite a la idea de pureza y así lo expreso.

Nishida acaba en este punto la disquisición entre signo y símbolo, pasando en las siguientes secciones a cuestionar la complicada red de categorías, entre ellas, ésta de la causalidad. Es por esta razón que aunque la referencia textual precedente sobre el símbolo es importante, no aclara ni propicia el encaje entre el simbolismo filosófico y la fundamentación artística y estética sobre la que discurrirá el filósofo pero ya en la parte final de Intuición y reflexión en la autoconciencia. Es allí donde encontramos la segunda formulación del simbolismo, allí sí, en directa relación con los poetas simbolistas.

42 Ibídem, p. 14 (NZK2-pp. 32-33). 
Llegado a la penúltima sección de la obra titulada «Varios Mundos» («Shuju no Sekai») [《種々の世界»], Nishida ya ha construido gran parte su sistema formal de la autoconciencia. Ha hecho pivotar todo el sistema alrededor de la autoconciencia como espacio donde se vinculan intuición y reflexión, siguiendo en esto la familiaridad que él reconoce entre su idea y los fundamentos filosóficos del ego trascendental de Johann Gottlieb Fichte (1762-1814) y su Tathandlung (unión de hecho y acto en la conciencia) ${ }^{43}$, en los que se respalda.

La filosofía del acto fichteana teje la interdependencia entre epistemología y filosofía práctica (ética) y se muestra, sin duda alguna, como un apoyo ineludible para el filósofo japonés y su proyecto filosófico que aspira a la superación de la fragmentación del sujeto en los compartimentos estancos de la cognición y la actuación. Como la identidad y la historia personal del sujeto no deben considerarse desde una perspectiva de la autoconciencia confinada en sí misma, sin externalidad, si la conciencia es activa, no puede negarse que será también autónoma, espontánea, creativa ${ }^{44}$. Un ejemplo de la autonomía, la espontaneidad y de la externalidad expresiva (emergente, manifiesta) es la de la intuición artística. Nishida elude, con la reivindicación de la intuición artística, que el sistema de la autoconciencia pueda resquebrajarse siendo tildado de no otra cosa más que una máscara para el psicologismo solipsista. Pues la intuición artística se desarrolla en la exterioridad artística y, como no, también en la literaria.

Por definición, la intuición artística engloba en sí dos aspectos aparentemente contradictorios pero que funcionan al unísono. Desde el lado de la intuición, Nishida conecta la llamada «intuición artística» con la subjetividad movida por una fuerza interna creativa que debe ser espontánea y autónoma. Esa intuición es la de la conciencia de la progresión intacta (ininterrumpida) que no ha sufrido la individuación pero que funciona al unísono con ella: sin intuición acompañada de reflexividad, no se puede producir la expresión artística y su materialización final en la obra de arte. El artista cuenta con la intuición: esa materia prima indeterminada e indefinida donde aún no se ha dado la separación entre sujeto y objeto. Pero a la vez y de manera recíprocamente dependiente, cuenta con la reflexión que es el movimiento que sale de la progresión indefinida, se voltea y, en volver sobre sí, re-presenta o ex-presa. El artista ejemplifica el proceso del sistema de autoconciencia donde un «es» tiende hacia un «deber ser» - la subjetividad del artista está movida por una

43 Ibídem, p. xix (NKZ2-p. 3). En Fichte, el neologismo Tathandlung quería dar cuenta de la identidad del agente y del hecho. Por eso, autores como Félix Duque lo traducen por «acción de hecho» que recoge esa relación entre acto y hecho: «La Tathandlung es una acción reflexiva en y por la cual se produce el hecho de mi conciencia: casi como si un hipercartesiano dijera: Ergo cogitat, ergo est. Pero, al tratarse de un postulado, ha de probarse, en una tarea asintótica de aproximación, la identidad final — «de hecho»—, inalcanzable-de acción y hecho. De aquí surge toda la filosofía de Fichte», en DuQue, F., Historia de la filosofía moderna: la era de la crítica, Ediciones Akal, Madrid 1998, pp. 209-210, n. 400.

44 NisHIDA, Intuition and Reflection in Self-consciousness; cit., p. 34 (NKZ2-p. 66). 
fuerza, la de la creatividad, que es y que aspira a materializarse en un «deber ser» ideado. A través de la mediación del «es»-«deber ser», o la intuición, en apariencia simple e irreflexiva, y el elemento reflexivo que obedece al «deber ser», se mueve la expresión artística.

La noción de «expresión» (hyogen-表現) como actividad propia del artista, la toma Nishida de la obra de Konrad Fiedler (1841-1895) ${ }^{45}$. En palabras de IwAKI Ken'ichi ${ }^{46}$, Fiedler no sólo es determinante para entender cómo piensa Nishida la creación artística, sino que le sirve para explicar mejor el desarrollo y diferenciación de la Realidad y la formación de la autoconciencia en tanto que el lugar donde se produce una relación dinámica entre intuición y reflexión, entre sujeto y objeto o mente y cuerpo en el mundo. Y, lo que es más importante, le sirve para teorizar el vínculo entre la trascendencia y la experiencia humana (inmanente). En definitiva, la conjunción entre el sistema perceptivo y experiencial del ser con su voluntad libre absoluta (zettai jiy û no ishi) [絶対自由の意 志].

Justamente la citación concreta de la poesía simbolista aparece como correlato a ese impulso hacia la trascendencia que, en pura lógica, queda más allá de la razón meramente teorética, de la posibilidad de conocimiento del ser humano. La Realidad primaria, originaria, unitaria, es prefigurada como la voluntad libre absoluta que constituye el mundo simbólico. Para Nishida, el mundo simbólico es el mundo de las relaciones de la libre voluntad, de las actividades puras del espíritu. Mundo simbólico al que, según Nishida, acceden los poetas simbolistas porque ellos son capaces de expresar la desintegración de las categorías con las que ordenamos el mundo y leen la Realidad en su pura correspondencia:

Es un mundo en el que no hay ni tiempo, ni espacio, ni causalidad y en el cual, según declaran los poetas simbolistas, cada cosa que se ve y se escucha es un símbolo, e incluso la ciencia y las matemáticas se convierten en una canción de la fiesta en el reino de la Flor Azul ${ }^{47}$.

Los poetas simbolistas o, en el sentido literal en el texto, la poesía de la escuela simbolista (shõchõha no shi-象徵派の詩), son capaces de traspasar y trascender todas las categorías y, por tanto, acceder, con su poesía, a la Realidad primaria que no es otra que la de las relaciones voluntarias, de la voluntad libre absoluta. Y, para Nishida, al trascender con su poesía todas las categorías que dividen el mundo y lo fragmentan, pueden declarar que todo lo que vemos y oímos mediado con las categorías, no es otra cosa que un símbolo, una señal por la que acceder a la Realidad en su carácter primigenio, originario y unitario.

45 En particular, del ensayo «Sobre el origen de la actividad artística» («Über den Ursprung der künstlerischen Tätigkeit») (1887) incluido en la obra Fiedler Escritos sobre arte (Schriften über Kunst). En castellano se encuentra traducido en FIEDLER, K., Escritos sobre arte. Traducción de Vicente Romano, revisión de la traducción e introducción de Francisca Pérez Carreño, Visor, Madrid 1991, pp. 169-290.

46 IWAKI, art. cit., pp. 270-271.

47 Nishid, Intuition and Reflection in Self-consciousness; cit., p. 156 (NKZ2-p. 318). 
Parece que este texto sí que nos acerca a la clave y al motivo preciso tras la citación expresa que hace Nishida de la poesía simbolista. Para la filosofía, igual que para este tipo de poesía, debería ser posible romper las cadenas de las relaciones duales que la encierran en los esquemas de las categorías. El poeta simbolista es capaz de quebrar las antiguas categorías poéticas que lo encerraban en la simple explicación de los fenómenos. Si recordamos las palabras del poeta Kitahara que mencionamos antes, la ruptura de la simple categorización esquemática es la vía poética que propicia la «intimación», por tanto, la correspondencia y transfiguración del orden impuesto exteriormente (en la razón teorética, cognoscitiva) con la Realidad tal y como ésta originariamente es. En paralelo, del argumento nishidiano se puede deducir que éste afirma que para cualquier persona es posible acceder, al igual que lo hacen el poeta o el artista, a ese mundo donde todo lo que se ve o se oye, todo objeto particularizado, no es nada más que un símbolo que se correlaciona siempre con la actividad profunda e infinita de los actos de la voluntad libre y creativa y, en definitiva, con la Realidad.

Siguiendo las premisas nishidianas, en la poesía y en el mundo simbólico al que accede el poeta-filósofo movido por la voluntad libre absoluta, la razón teorética y sus ámbitos de conocimiento (como puedan ser la ciencia y las matemáticas) se transfiguran en canción, en la métrica armónica del verso. Son parte del «reino de la Flor Azul», en clara alusión a la carga simbólica de la «flor azul» que encontramos en la novela inacabada de Friedrich von Hardenberg, Novalis, (1772-1801), Enrique de Ofterdingen ${ }^{48}$.

Es posible imaginar qué intención hay tras la mención del símbolo de la «flor azul» de Novalis. Como es natural, a Novalis no se le puede incluir dentro de la escuela simbolista pero, en la identificación que hace Nishida entre los poetas simbolistas y Novalis, no hay nada extraño o anacrónico. Parece, más bien, que hay una inteligente agudeza con la que Nishida emparenta a la poesía simbolista del siglo XIX con el idealismo filosófico-simbolista que impulsa la intención expresiva del alemán. Porque como elemento subyacente en la producción literaria de Novalis no hay sólo un puro ejercicio literario o estético sino una determinante aunque, en ocasiones obviada, filosofía ${ }^{49}$. Unos

48 Véase Novalis, Himnos a la noche. Enrique de Ofterdingen. Edición y Traducción de Eustaquio Barjau, $4^{\mathrm{a}}$ edición, Ediciones Cátedra, Madrid 2008. Cabe mencionar que la visión de la flor azul en sueños se desencadena en el personaje de Enrique tras el relato de un extranjero que ha visitado a la familia Ofterdingen y que es el que despierta su anhelo por encontrar la flor y realizarla como poesía. Es fundamental la figura del extranjero y las diversas formas que adquiere a lo largo de la novela: los guerreros, el minero, el personaje de la muchacha oriental Zulima que representa al país de la poesía,... y cómo su contacto con ellos le acerca más a su deseo de llegar al significado completo de la flor azul.

49 Filosofía que está presente de una manera radical en la antología de sus escritos filosóficos conocida con el título de Estudios sobre Fichte. En las anotaciones filosóficas en forma telegráfica, de fragmentos de ideas, Novalis completa y contribuye a la discusión filosófica de la época, a la filosofía del sujeto y a la reflexión sobre cuestiones de estética tan importantes para comprender mejor el idealismo alemán. Por lo demás, habría un interesante diálogo filosófico en el ámbito comparativo de estudiarse algunas de las ideas de Novalis en relación 
principios filosóficos que, en palabras de Barjau en su introducción crítica a la traducción de la novela de Novalis, se sustentan en una intuición intelectual activa, en una proyección activa del sujeto sobre el objeto que conoce, una acción del ser humano sobre las cosas y un entendimiento capaz de asir la correspondencia hombre-mundo ${ }^{50}$. Intuición activa que, por otro lado, encontramos en la intuición artística de Nishida y que sitúa al sujeto en el medio propicio para el reconocimiento de esa correspondencia entre el hombre y el mundo y, por tanto, para la reunificación de lo disgregado cognostivamente.

Con estas indicaciones ya es posible establecer dónde está el punto de unión e importancia entre algunos de los trazos definidores de la poesía simbolista, la tarea del poeta y la argumentación filosófica de Nishida.

Si recordamos nuevamente el texto de Kanbara y el modo en el que teorizaba acerca de las posibilidades expresivas de la moderna poesía simbolista, sus palabras están en diálogo y sincronía con lo dicho en este punto sobre la filosofía de Nishida. Pues las ideas de Kanbara respecto a la poesía simbolista resuenan claramente en la consideración del «mundo simbólico» nishidiano que se mueve en intenciones altamente equivalentes. Con ello, es posible afirmar que la referencia expresa a la poesía simbolista por parte del pensador no es una cuestión de mera accidentalidad sino que refuerza la trabazón entre su epistemología (cómo conocer) y la ontología (cómo es la Realidad). Por consiguiente, se puede sostener que la poesía simbolista le sirve a Nishida para reforzar y completar el entramado proposicional de su sistema. Y, especialmente, fortalecer esa asunción de que el sujeto, en este caso en el mundo del arte, puede asociar, reunir, reunificar lo que se le aparece disgregado - unir, en definitiva, su yo con el mundo. Un camino, el de la expresividad poética y su linaje de copertenencia con la filosofía, que ayudaría al examen, en palabras de Kanbara, de las «relaciones mutuas» entre los fenómenos del mundo externo y el yo y, por tanto, del nivel en el que es posible participar en la vida donde las ondulaciones entre los mundos, las resonancias, se multiplican. Incluso si, como dice Nishida más adelante, ese yo que llega a participar de las resonancias entre el mundo interior y el exterior con el arte, vive en un mundo de misterio -misterio que, según Nishida, los simbolistas consideran como algo implícito en todos los fenómenos ${ }^{51}$.

con las de Nishida, por ejemplo, en lo tocante al sentido de la autoconciencia y la intuición. Leer fragmentos como el siguiente reubican en un plano más amplio el particular idealismo del mismo Nishida: «La acción originaria es la unidad de sentimiento y reflexión en la reflexión. La intuición intelectual es su unidad fuera de la reflexión. Ya que todo lo pensado es reflexión, la intuición intelectual, ciertamente, también será pensada en las formas de la acción originaria - pero aquí tenemos que hacer abstracción de esto. En el origen precede a la acción originaria. La fundamenta — de modo secundario es al revés. Es una relación parecida a la que se da entre conciencia pura y reflexiva», en Novalis, Estudios sobre Fichte y otros escritos. Edición de R. Caner-Liese, Akal, Madrid 2007, p. 48.

50 BaRJau, E., "Introducción», en Novalis, Himnos a la noche. Enrique de Ofterdingen; cit., pp. 18-19.

51 NisHida, Intuition and Reflection in Self-consciousness; cit., p. 156 (NKZ2-p. 319). 
Para completar y finalizar este apartado apuntalando así esta encontrada y demostrada sincronía teórica entre los principios de la poesía simbolista y algunas de las ideas que nutren la primera etapa de Nishida, pasamos ahora a indicar otra referencia textual que nos parece fundamental para el propósito de este estudio. En este caso, nos dirigimos a un trabajo que, aunque posterior a Intuición y reflexión en la autoconciencia, se mueve en el mismo espectro temático sobre la conciencia, la voluntad, el arte y la expresión. Nos referimos a la colección de ensayos publicada en el año 1920, Cuestiones sobre la conciencia (Ishiki no mondai) [意識の問題] ${ }^{52}$. Allí es donde encontramos referencias directas a la poesía de Rimbaud y Baudelaire. Esto sucede, en concreto, en dos ensayos: «Emoción»(«Kanjõ») (《感情») ${ }^{53} \mathrm{y}$ «El verdadero significado de los símbolos» («Shõchõ no shinigi») [象徵の真意義] $]^{54}$.

En el primero, Nishida cita a Rimbaud y a Baudelaire en el contexto de su elucidación sobre la «emoción» (kanjõ) y su diferenciación filosófica respecto a la «sensación» (kankaku-感覚) entendida ésta última en un sentido estricto como la percepción mediante los sentidos.

Para Nishida, aunque emoción y sensación son ambas fenómenos mentales que siguen la misma estructura de «significado-como-realidad», la diferencia entre ambas reside en su grado de unificación: si la sensación depende de un mínimo contenido de unidad consciente, la emoción reúne un contenido más completo que engloba diversos impulsos no sólo sensitivos, sino también intelectuales. En ella, por tanto, se unifican las cualidades que, en una más completa adición que la de las simples «sensaciones», traspasan el desnudo apego de la percepción mediante los sentidos. La emoción, por tanto, queda más allá de esa experiencia solamente considerada a posteriori (que tiene su origen en la experiencia perceptiva) y configura lo que Nishida denomina como «a priori de los a priori». A pesar de la vaguedad con la que Nishida presenta éste apriorismo del apriorismo, parece, por el contexto, que al hablar de este absoluto apriorismo de la emoción lo que hace es fundamentar el carácter absoluto y no ya parcial o fragmentario de las facultades del sujeto en juego.

En ese contexto es donde encontramos las referencias, que Nishida transcribe en su original francés, al verso inicial del conocido poema de Rimbaud,

${ }^{52}$ Ishiki no mondai en Nishida, K., Nishida Kitarõ Zenshû; AвE, Y. to Henshû, Vol. 3, Iwanami Shoten, Tokyo 1965, pp. 3-326.

53 Está disponible una traducción parcial del texto al inglés realizada por David Dilworth y Valdo H. Viglielmo en Nitta, Y., Tatematsu, H. (Eds.), Japanese Phenomenology. Phenomenology as the Trans-cultural Philosophical Approach, Analecta Husserliana, Vol. III, D. Reidel, Dordrecht / Boston / London 1979, pp. 223-247. En japonés en Ishiki no mondai, NisHidA, Nishida Kitarõ Zenshû, Vol. 3, cit., pp. 51-77.

${ }^{54}$ En Ishiki no mondai en Nishida, Nishida Kitarõ Zenshû, Vol. 3, cit., pp. 78-82. 
«Vocales» («Voyelles»)5 ${ }^{55}$, y al octavo verso del poema de Baudelaire, «Correspondencias» («Correspondances») ${ }^{56}$ :

(...) La emoción puede ser descrita como la unidad implícita de varios impulsos intelectuales. Puede considerarse como el a priori del a priori. Cuando Rimbaud escribe «A noir, E blanc, I rouge, U vert, O bleu» [«A negra, E blanca, I roja, U verde, $\mathrm{O}$ azul»] o cuando Baudelaire dice «les parfums, les couleurs et les sons se répondent» [«los perfumes, los colores y los sonidos se responden»], la fusión de las cualidades emotivas a las que refieren debe entenderse sobre la base de la «emoción». Con frecuencia, la emoción se describe como pasiva, pero yo no estoy de acuerdo. Cito el ejemplo de Goethe quien, al transformar su vida en su poesía, lograba superar sus aflicciones. De manera similar, llegamos a ser libres en el momento en el que abrazamos y trascendemos el intelecto en este estadio descrito de la emoción ${ }^{57}$.

$\mathrm{El}$ alcance de estas citaciones ya nos resulta conocido gracias a lo expuesto con anterioridad. Esto es así si nos fijamos en que encontramos nuevamente esa comparación entre el poeta y el filósofo en la que, en ocasiones, el filósofo aparece como encerrado en el interior de un esquema epistemológico que desdeña lo que el poeta consigue y aprecia: la intuición de la correspondencia entre la infinitud de lo real con la finitud de los fenómenos que la conforman para nosotros, en palabras acertadas de Viglielmo ${ }^{58}$. En el estudio de Viglielmo sobre los primeros años de formación filosófica de Nishida, esta autor recoge perfectamente esta idea cuando indica que ya en sus primeros escritos breves pertenecientes a su etapa de formación, el filósofo japonés insiste en la comparación entre el poeta y el filósofo. Comparación en la que, ciertamente, el filósofo y, por tanto, la filosofía, queda en desventaja cuando su mirada solamente prioriza la facultad cognoscitiva y acentúa la ansiada objetividad del conocimiento por encima de otros ámbitos de conocimiento que rechaza por ser hueros juegos subjetivos. Para Nishida, y ésta es una de las constantes en toda su obra filosófica, hay una jerarquía valorativa favorable respecto al arte y la religión. Refiere con frecuencia al arte y a la religión como ámbitos en los que se han solucionado los problemas (por ejemplo, el de la unificación y superación de los dualismos) que él quiere, no obstante, solucionar también en el campo filosófico y con los útiles de la filosofía. Con esto es posible corroborar, compartiendo en este punto la misma posición de Viglielmo, una inferencia interpretativa básica que nos indicaría que cuando Nishida fija la vista en los poetas simbolistas, éstos representan para él un patrón posible y a seguir con las herramientas de la filosofía.

55 Véase en Rimbaud, A., Poesías y otros textos. Traducción y notas de Juan Abeleira, edición Bilingüe, Madrid: Ediciones Hiperión, 2a edición revisada, 1991, pp. 114-119.

56 Véase en Baudelaire, C., Poesía completa. Edición Bilingüe, Ediciones 29, Barcelona 1994, pp. 46-47.

57 En Ishiki no mondai en NishidA, Nishida Kitarõ Zenshû, Vol. 3., cit., p. 62.

58 Viglielmo, Valdo H., «Nishida Kitarõ: The Early Years», en Shively, D. H. (Ed.), Tradition and Modernization in Japanese Culture, Princeton University Press, Princeton 1976, pp. 551-552. 
Como dice Viglielmo, no sería una exageración ver en este proceder de Nishida su anhelo por descubrir la Realidad con las herramientas filosóficas al igual que el poeta y el artista lo hacen con su lápiz o su pincel ${ }^{59}$.

Así se evidencia también y de una manera más clara aún, en el estudio sobre el símbolo que centra el ensayo «El verdadero significado de los símbolos». En él, retomando la cuestión relativa al vínculo entre significado y existencia, vemos que Nishida vislumbra que el poema de Baudelaire, «El hombre y el mar» ( L'homme et la mer») ${ }^{60}$, del que transcribe en francés los primeros ocho versos, responde exactamente a esa posibilidad unificadora y de correspondencia correlativa entre el hombre y la naturaleza. En el poema, la imagen es la del mar que funciona como alter ego del hombre en el que ve reflejadas sus cualidades y vicisitudes (El mar es tu espejo; contemplas tu alma / en el desarrollo infinito de su lámina, / y tu espíritu no es un abismo menos amargo).

Este ensayo es esencial no sólo para fijar en qué medida los poetas simbolistas representan, en el campo de la poesía, aquello que pugna por conseguir Nishida en la filosofía. Es también esencial para una línea interpretativa de la filosofía nishidiana que tenga en cuenta cómo, tras su modo particular de concebir el arte, la obra de arte puede leerse como una correlación de la personalidad individual del artista que queda impresa en ella. Tarea de la filosofía es conseguir lo mismo.

\section{Consideraciones finales}

Al principio de este trabajo se fijaron los objetivos de este estudio. Desde una perspectiva general, se trataba de indicar los puntos básicos que hacen posible conectar la filosofía de Nishida con la recepción del movimiento literario simbolista en Japón. Para cumplir con tal objetivo, primeramente se expuso la conceptualización de «símbolo» en el Japón Meiji por parte de Nakae para mostrar las implicaciones y el sentido del término. Tanto en el caso de la traducción de «símbolo» como en el proceso paralelo en el caso de la creación terminológica de «metafísica» de Nishi, la contextualización mostró cómo las implicaciones sobre la trascendencia y la inmanencia se imprimen no sólo en la poesía simbolista japonesa sino también en la filosofía de Nishida.

Asimismo, la exposición sobre la recepción y la repercusión del movimiento literario simbolista europeo en los círculos intelectuales japoneses ha proporcionado que, en diálogo directo con la subsiguiente interpretación de los textos de Nishida, sea posible confirmar que la apreciación de los poetas simbolistas no es una cuestión aislada en los márgenes de su obra filosófica. Uniendo las teorías sobre la nueva forma poética en boca de los poetas japoneses, como Kitahara y Kanbara, con el modo en el que Nishida se respalda en algunos rasgos definidores de la poesía simbolista, es posible afirmar que el simbolismo se

59 Ibídem, p. 552.

60 Baudelaire, Poesía completa, cit. pp. 64-67. 
entreteje como movimiento literario importante y a tener en cuenta para conocer de un modo más completo la diversidad y complejidad de la historia intelectual del Japón moderno. Respecto al análisis de las influencias mutuas entre Japón y los movimientos literarios europeos queda mucho por hacer. Aquí no se ha abordado pero sería beneficioso poner en interlocución, intencionalmente cruzada, las influencias que al mismo tiempo se producen en Europa con la recepción, apreciación y proliferación de poesía siguiendo la escritura de haiku.

En lo tocante al objetivo más concreto, a saber, cuestionar en qué medida y cómo las referencias al movimiento simbolista presentes en los primeros ensayos de Nishida mencionados le ayudan a reforzar sus propio sistema de la autoconciencia y, por extensión, su construcción de una subjetividad no dual y abarcadora de las perspectivas que fragmentan al sujeto en sus diferentes facultades (cognoscitiva, ética y estética), también ha sido posible llegar a alguna aclaración significativa aunque no totalmente conclusiva. Entre otras cosas porque, por ejemplo, quedaría más por hacer respecto a las implicaciones éticas.

La aclaración significativa a la que este estudio llega se puede resumir, en síntesis, en haber encontrado que Nishida valora la poesía simbolista como patrón para conseguir las metas a las se dirige su sistema de la autoconciencia. En concreto, hemos visto cómo para Nishida la poesía prefigura la posibilidad y el modo en el que la filosofía puede llegar a superar el dualismo. Dualismo que, desde la perspectiva nishidiana, no hace otra cosa que fragmentar la Realidad y llevarnos a un conocimiento erróneo sobre ella o, como mucho, a uno siempre parcial y escindido. El mundo del arte y los poetas simbolistas asocian, reúnen y reunifican lo que aparece y se explica desde la filosofía como separable y disgregado substancialmente. Entre otras cosas, según se infiere de las premisas nishidianas, por una mal comprendida abstracción que acaba ampliando el ámbito estricto de la reflexión como facultad y que, obviando el papel de la intuición, separa al hombre del mundo. Como se ha visto, Nishida valora en la expresividad poética simbolista la materialización literaria de las relaciones mutuas e interdependientes entre el mundo y el yo recobrando, así, la corresponsalía indeclinable que él quiere recuperar también en la filosofía.

La cuestión abierta que aquí no se ha tratado, pues excede en mucho lo que estrictamente se quería estudiar, es si efectivamente es posible la superación de los problemas que plantea el dualismo. O si, por el contrario y tal y como enuncia el filósofo alemán que tan bien conocía Nishida, Wilhelm Windelband (1848-1915), en su obra Introducción a la filosofía (Einleitung in die Philosophie) (1914) ${ }^{61}$, no podemos salir de la contradicción en la que caemos cogidos entre el dualismo y el monismo. Pues para Windelband, el dualismo constituye el más cierto de todos los hechos aunque, a su vez, el monismo sea la más sólida de todas las asunciones a las que llega la filosofía de la realidad. Porque

61 Según explica Yusa, Nishida utiliza la obra de Windelband Introducción a la filosofía como manual en sus clases de los años en los que redacta Intuición y Reflexión en la autoconciencia. Véase Yusa, op. cit., p. 134. 
bien puede suceder que, como insinúa Windelband, cuando se intenta explicar cómo el uno se divide en dos para luego retornar a la unidad originaria, quizás sea posible definir el proceso dialéctico pero no dar solución al problema que marca los límites de nuestro conocimiento ${ }^{62}$.

La resolución de la dialéctica entre el yo y el mundo y su unificación es defendida, como se ha visto, por un Nishida respaldado en el mundo simbólico de los poetas simbolistas. Pero queda abierta la cuestión no sobre el «qué», sino sobre el "cómo»: cómo defender una no-dualidad en la filosofía que no se transfigure, al final, en un puro misticismo.

\section{BiBLIOGRAFÍA}

Angles, J. (2003). «The Heritage of Symbolism: The «Aesthetic» Style of Kitahara Hakushû and Murayama Kaita», PAJLS-Proceedings of the Association for Japanese Literary Studies-Japanese Poeticity and Narrativity Revisited, Vol. 4, Summer, pp. 237-263.

Baudelaire, C. (1994). Poesía completa, Edición Bilingüe. Barcelona: Ediciones 29.

Cheng, A. (2006). Historia del pensamiento chino. Traducción de Anne-Hèléne Suárez Girard. Barcelona: Edicions Bellaterra.

Duque, F. (1998). Historia de la filosofía moderna: la era de la crítica. Madrid: Ediciones Akal.

Ferrater Mora, J. (2004). Diccionario de Filosofía. Barcelona: Ariel, 3a. Reimpresión.

Fiedler, K. (1991). Escritos sobre arte. Traducción de Vicente Romano, revisión de la traducción e introducción de Francisca Pérez Carreño. Madrid: Visor.

Galik, M. (2001). "Some Remarks on Symbolism in the Far Eastern Interliterary Process», en Mrugalla, A., Gössmann, H. (Eds.), Deutschsprachiger Japanologentag in Trier 1999, Vol. 2. Münster: Lit Verlag, pp. 211-218.

Gómez Bedate, P. (1985). Mallarmé. Madrid: Ediciones Júcar.

González Valles, J. (2002). Historia de la filosofía japonesa. Madrid: Tecnos.

Heisig, J. W. (2002). Filósofos de la Nada. Un ensayo sobre la Escuela de Kioto. Barcelona: Editorial Herder.

Henrich, D. (1994). The Unity of Reason. Essays on Kant's Philosophy. Velkley, R. L. (Ed.), Edwards, J., Hunt, L., Kuehn, M. and Zoeller, G. (Transl.). London: Harvard University Press.

- (2003). Between Kant and Hegel. Lectures on German Idealism. Pacini, D. S. (Ed.). Cambridge-London: Harvard University Press.

Iwaki, K. (2001). "Nishida Kitarõ and Art», en Marra, M. F. (Ed. \& Transl.), A History of Modern Japanese Aesthetics. Honolulu: Hawai'i University Press, pp. 259-284.

Jackson, E., Jr. (1990). «The Metaphysics of Translation and the Origins of Symbolist Poetics in Meiji Japan», PMLA (Modern Language Association), Vol. 105, No. 2, pp. 256-272.

- (1991). "The Heresy of Meaning: Japanese Symbolist Poetry», Harvard Journal of Asiatic Studies, Vol. 51, No. 2, pp. 561-598.

Karatani, K. (1993). Origins of Modern Japanese Literature. Brett De Bary (Transl. \& Ed.). Durham and London: Duke University Press.

62 Windelband, W., An Introduction to Philosophy; Translated by Joseph McCabe, London: T. Fisher Unwin Ltd., 1921, pp. 358-359. 
Lippit, N. M. (1997). «The Grotesque and the Quest for Supernal Beauty», Comparative Literature, Vol. 29, No. 3, pp. 221-240.

Marback, R. C. (1994). «Rethinking Plato's Legacy: Neoplatonic Readings of Plato's Sophist», Rhetoric Review, Vol. 13, No. 1, pp. 30-49.

Marra, M. (1999). Modern Japanese Aesthetics. A Reader. Honolulu: Hawai'i University Press.

Nishida, K. (1965). Nishida Kitarõ Zenshû. ABE Yoshishige to Henshû, Vol. 2 y Vol. 3. Tokyo: Iwanami Shoten.

- (1987). Intuition and Reflection in Self-consciousness. Translated by Valdo H. Viglielmo with Takeuchi Yoshinori and Joseph S. O’Leary. New York: State University of New York Press-SUNY.

Nitta, Y., Tatematsu, H. (Eds.) (1979). Japanese Phenomenology. Phenomenology as the Trans-cultural Philosophical Approach, Analecta Husserliana, Vol. III. Dordrecht / Boston / London: D. Reidel.

Novalis (2007). Estudios sobre Fichte y otros escritos. Edición de Caner-Liese, R. Madrid: Akal.

- (2008). Himnos a la noche. Enrique de Ofterdingen. Edición y Traducción de Eustaquio Barjau. Madrid: Ediciones Cátedra, $4^{\text {a }}$ Edición.

Piovesana, G. (1997). Recent Japanese Philosophical Thought 1862-1962. A Survey. With a New Survey (1963-96) by YAMAWAKI, N.; 3rd. Revised Edition. Richmond-Surrey: Japan Library-Curzon Press.

Poe, E. A., Baudelaire, C., Mallarmé, S., Valéry, P., Eliot, T. S. (2011). Matemática tiniebla. Genealogía de la poesía moderna. Idea, selección y prólogo de Antoni Marí, traducción de Miguel Casado y Jordi Doce. Madrid: Galaxia Gutenberg-Círculo de Lectores.

Rimbaud, A. (1991). Poesías y otros textos. Traducción y notas de Juan Abeleira, Edición Bilingüe. Madrid: Ediciones Hiperión, $2^{\text {a }}$ edición revisada.

Stevens, B. (2008). Invitación a la filosofía japonesa. En torno a Nishida. Traducción de José Miguel Marcén. Barcelona: Edicions Bellaterra.

Symons, A. (1908). The Symbolist Movement in Literature. New York: E. P. Dutton \& Co.

Tremblay, J. (2003). «Introduction de la traductrice», en Nishida, K., L'Eveil à soi. Traducción de Jacynthe Tremblay. París: CNRS, pp. 9-51.

VV.AA., Diccionario de la Real Academia Española en línea-Vigésima segunda edición. URL: www.rae.es

Verlaine, P. (1987). Los poetas malditos y otros textos. Traducción, prólogo y notas de Mauricio Bacarisse. Madrid: Ediciones Júcar.

- (1992). Poesía; Introducción, traducción en verso y notas de Carlos Pujol. Barcelona: Editorial Planeta.

Viglielmo, V. H. (1976). «Nishida Kitarõ: The Early Years», en Shively, D. H. (Ed.), Tradition and Modernization in Japanese Culture. Princeton: Princeton University Press, pp. 507-562.

Windelband, W. (1921). An Introduction to Philosophy. Translated by Joseph McCabe. London: T. Fisher Unwin Ltd.

Yusa, M. (2002). Zen and Philosophy. An Intellectual biography of Nishida Kitarõ. Honolulu: Hawai'i University Press.

Universidad de Barcelona

Departamento de Barcelona

Monserrat Crespín Perales

m.crespin@ub.edu

[Artículo aprobado para publicación en diciembre de 2012]

Revisado con posterioridad para su publicación 